\title{
EDUCAÇÃO AMBIENTAL E OS DESAFIOS PARA O DESENVOLVIMENTO SUSTENTÁVEL
}

Serli Genz Bölter ${ }^{1}$; Sandra Vidal Nogueira ${ }^{2}$

\section{RESUMO}

A pesquisa integra o projeto Demandas pelo direito e desenvolvimento na região noroeste do Estado do Rio Grande do Sul, do Grupo de Pesquisa Direitos Humanos, Movimentos Sociais e Instituições - G.DIR.SOCIAIS/UFFS e busca aprofundar a noção de desenvolvimento sustentável e a teoria do bem viver. A análise parte da normatização do Direito Ambiental na Constituição Federal de 1988 e das normas jurídicas que disciplinam sobre a Educação Ambiental no Brasil. Afirma-se que são necessários novos paradigmas na relação homem - natureza. A pesquisa é de revisão bibliográfica e está vinculada ao Programa de Mestrado em Desenvolvimento e Políticas Públicas da Universidade Federal da Fronteira Sul, Campus Cerro Largo, RS.

Palavras-chave: Direito ambiental; Educação ambiental; Desenvolvimento sustentável.

\section{ENVIRONMENTAL EDUCATION AND THE CHALLENGES TO SUSTAINABLE DEVELOPMENT}

\begin{abstract}
The research is part of the Demands for Law and Development project in the northwestern region of the State of Rio Grande do Sul, of the Research Group Human Rights, Social Movements and Institutions - G.DIR.SOCIAIS / UFFS, RS and seeks to deepen the notion of sustainable development and the theory of good living. The analysis starts from the normalization of Environmental Law in the Federal Constitution of 1988 and from the legal norms that discipline Environmental Education in Brazil. It is argued that new paradigms are needed in the man-nature relationship. The research is a bibliographical review and is linked to the Master Program in Public Policy and Development of the Federal University of the South Frontier, Campus Cerro Largo, RS.
\end{abstract}

Keywords: Environmental law; Environmental education; Sustainable development.

1 Doutora em Sociologia (UFRGS). Professora da Universidade Federal da Fronteira Sul, vinculada ao Programa de Mestrado em Desenvolvimento e Políticas Públicas, Campus de Cerro Largo, RS. E-mail: serli.bolter@uffs.edu.br.

2 Doutora em Educação (USP). Professora da Universidade Federal da Fronteira Sul, vinculada ao Programa de Mestrado em Desenvolvimento e Políticas Públicas, Campus de Cerro Largo, RS. E-mail: sandra.nogueira@uffs.edu.br. 


\section{Introdução}

A preocupação com as questões ambientais e a necessidade de definir um modelo de desenvolvimento sustentável são desafios da modernidade. A organização da sociedade moderna, que tem o Estado como produtor da ordem jurídica, política e social, deve disciplinar o modelo econômico e, consequentemente definir os programas de desenvolvimento que serão implementados. No Brasil a definição jurídica da Constituição Federal de 1988 aponta para a definição de uma política econômica alicerçada no sistema capitalista que deve assegurar uma ordem de sustentabilidade econômica pois prevê cuidados com o ambiente que assegurem um ambiente equilibrado e garantido para as presentes e futuras gerações. Os princípios do desenvolvimento sustentável e intergeracional nas questões ambientais estão presentes nos arts. 170 e 225 da Constituição Federal de 1988 e revelam a adoção de um sistema que precisa vincular-se a novos preceitos na relação homem e natureza.

Considerando estes preceitos constitucionais o artigo afirma que os conceitos de desenvolvimento no Brasil devem alinhar-se com uma perspectiva teórica de desenvolvimento sustentável e de proteção ao ambiente. É inegável que as relações de uso e apropriação da natureza tem apontado para a inviabilidade de vida no planeta. Os índices de agressão ao ambiente e o uso sem controle dos recursos naturais apontam para o esgotamento do modelo de desenvolvimento vigente, modelo que é caracterizado pelo paradigma antropocêntrico da relação do homem com a natureza. As catástrofes ambientais estão cada vez mais presentes. A finitude dos recursos é cada vez mais perceptível. E as consequências da degradação do ambiente apontam para situações de extermínio de biomas, de mudanças significativa no clima e de desastres ambientais de proporções cada vez maiores. Para exemplificar temos a ocorrência de catástrofes ambientais no mundo, gerando populações cada vez maiores de refugiados ambientais, ou para citar um caso de desastre ambiental no Brasil, temos Mariana em Minas Gerais.

O artigo apresenta no primeiro item uma retomada do modelo de Direito Ambiental e de normatização jurídica sobre a Educação Ambiental atualmente em vigor no Brasil. Resgate importante para evidenciar a necessidade de 
adoção de novas políticas de desenvolvimento que apontem para os preceitos de sustentabilidade que são formalmente assegurados na Constituição.

Trata, no segundo item a teoria do bem viver que apresentará a possibilidade de produção da ordem jurídica que reconheça a natureza como detentora de direitos. Esta perspectiva está se fortalecendo no contexto da América Latina, especialmente com a inclusão dos direitos da natureza nas constituições da Bolívia e do Equador. É necessário pensar o desenvolvimento em novos moldes de apropriação da natureza, construindo espaços de solidariedade, de partilha e de apropriação diferenciada que não leve ao esgotamento da natureza, ou seja, uma postura que precisa ser construída com os recursos e mecanismos da Educação Ambiental para todos, em todos os níveis e em todas as etapas da vida.

A pesquisa aponta algumas alternativas para o estudo sobre desenvolvimento sustentável e a relação com Educação Ambiental e integra o projeto Demandas pelo direito e desenvolvimento na região noroeste do Estado do Rio Grande do Sul, do Grupo de Pesquisa Direitos Humanos, Movimentos Sociais e Instituições - G.DIR.SOCIAIS/UFFS vinculado ao Programa de PósGraduação de Mestrado em Desenvolvimento e Políticas Públicas da Universidade Federal da Fronteira Sul, Campus Cerro Largo, RS.

\section{A autonomia do Direito Ambiental na Constituição Federal de 1988 e a previsão normativa sobre a educação ambiental}

Para apontar alguns desafios que envolvem a noção de desenvolvimento sustentável parte-se da previsão normativa sobre Direito Ambiental e sobre Educação Ambiental na Constituição Federal de 1988 e no conjunto da legislação infraconstitucional vigente no Brasil. A Constituição Federal, aprovada em 1988, permitiu avanços significativos na positivação das normas jurídicas ambientais. Podem ser indicados dois elementos que ilustram esses avanços: inicialmente a garantia de um meio ambiente ecologicamente equilibrado assegurado para as presentes e as futuras gerações (art. 225 $\mathrm{CF} / 88)^{3}$; e, como segundo, o princípio de que o desenvolvimento deve ser entendido sob a ótica do desenvolvimento sustentável e da proteção ao meio

3 Art. 225. Todos têm direito ao meio ambiente ecologicamente equilibrado, bem de uso comum do povo e essencial à sadia qualidade de vida, impondo-se ao Poder Público e à coletividade o dever de defendê-lo e preservá- lo para as presentes e futuras gerações. 
ambiente (art. 170 da CF/88) ${ }^{4}$. Tais preceitos indicam uma normatização que ultrapassa a perspectiva antropocêntrica do Direito Ambiental e aponta para a superação de uma noção de desenvolvimento restrito a crescimento econômico.

O Direito Ambiental Brasileiro precisa, portanto, consolidar-se na perspectiva de proteção e da consolidação de condições de manter um equilíbrio ambiental que garanta vida saudável para as presentes e futuras gerações. Afirma-se que o Direito Ambiental é elevado a uma classificação de direito fundamental da pessoa humana, baseado em uma concepção material e não apenas formal (DERANI, 2008). É uma concepção que sai da perspectiva de que o Direito ambiental pode ser classificado com bens da natureza que podem ser apropriados pelos seres humanos, e passa a condição de ter proteção jurídica.

A temática ambiental é uma questão que preocupa setores da sociedade desde as últimas décadas do século passado. Poderíamos exemplificar esta preocupação com a publicação de Primavera Silenciosa por Raquel Carson em 1962 nos Estados Unidos. Esse texto denuncia na época os impactos que o uso excessivo de agrotóxicos gerava. Ou ainda podem ser citadas as Conferências Ambientais Internacionais entre elas a de Estocolmo, em 1972, a Rio-92, a Rio+10, em 2002, a Rio+20 em 2012 e a Agenda 2030.

Essas Conferências e ações que denunciam os graves problemas relacionados com a falta de cuidados com o ambiente. Conferências que indicam para um modelo de expropriação dos bens naturais. Inclusive a terminologia jurídica utilizava termos com 'bens naturais", 'recursos naturais' que são indicativos de uma relação onde a natureza era patrimônio e mais, patrimônio que estava a disposição para integrar o patrimônio dos seres humanos. A necessidade de mudança desse paradigma é apontada nessas conferências, bem como são indicados os desafios para a construção de uma nova relação dos homens com a natureza.

4 Art. 170. A ordem econômica, fundada na valorização do trabalho humano e na livre iniciativa, tem por fim assegurar a todos existência digna, conforme os ditames da justiça social, observados os seguintes princípios:

$\mathrm{VI}$ - defesa do meio ambiente;

$\mathrm{VI}$ - defesa do meio ambiente, inclusive mediante tratamento diferenciado conforme o impacto ambiental dos produtos e serviços e de seus processos de elaboração e prestação; (Redação dada pela Emenda Constitucional no 042 , de 19.12.2003). 
Considerando o quadro de catástrofes ambientais e do reconhecimento de que o Direito Ambiental, tanto no direito interno como nas regras internacionais, é um direito que deve assegurar um ambiente equilibrado e de que os seres humanos precisam adequar as suas ações nas relações com a natureza é que se afirma a necessidade do estabelecimento de mecanismos para assegurar tais direitos para todos os cidadãos. Além da Constituição Federal de 1988 o ambiente é o tema inicial da normatização dos direitos difusos com a aprovação da Política Nacional de Meio Ambiente de 1981. Devem ser indicados como avanços dois instrumentos legais: a legitimidade do Ministério Público na proposição de Ação de Responsabilidade Civil e Criminal por danos ao meio ambiente e a Ação Civil Pública que, além do Ministério Público, pode ser movida pela Defensoria Pública, pela União, pelos estados e municípios, por autarquias, pelas empresas públicas, fundações e sociedades de economia mista e, ainda, associações com mais de um ano de existência e que incluam a proteção ao meio ambiente, ao consumidor e/ou patrimônio histórico e cultural entre suas finalidades. Estes dispositivos evidenciam normas de proteção e de criação de mecanismos de efetivação do Direito Ambiental.

O Brasil é, também, signatário do Acordo de Paris e, portanto, assumiu, o compromisso de implantar ações e medidas que apoiem o cumprimento das metas estabelecidas na NDC (Contribuição Nacionalmente Determinada). O Ministério do Meio Ambiente tem articulado a elaboração de uma Estratégia Nacional para a Implementação e o Financiamento da NDC (Contribuição Nacionalmente Determinada) do Brasil ao Acordo de Paris (Brasil, Ministério do Meio Ambiente, 2017, acessado em 10 de setembro de 2017). De forma mais detalhada, O Brasil se comprometeu a reduzir as emissões de gases de efeito estufa em 37\% até 2025 e apresentou o indicativo de redução de 43\%, até 2030. Ambos são comparados aos níveis de 2005. Entre outras medidas, o Acordo de Paris tem o objetivo de manter o aumento da temperatura média global a bem abaixo de $2^{\circ} \mathrm{C}$ em relação aos níveis pré-industriais e de garantir esforços para limitar o aumento da temperatura a $1,5^{\circ} \mathrm{C}$ (Brasil, Ministério do Meio Ambiente, 2017, acessado em 10 de setembro de 2017).

O debate sobre Educação Ambiental adquire relevo à medida que se constitui como uma das possibilidades de construção de novos pilares para os 
cuidados com a natureza. A Educação Ambiental tornou-se pauta de discussão de conferências mundiais, a partir da 1a Conferência das Nações Unidas sobre o Meio Ambiente em Estocolmo em 1972, que estabeleceu que a educação da população era necessária para desenvolver noções de responsabilidade de todos os seres humanos com a proteção e melhoria do meio ambiente (PELICIONI, 2005).

O Encontro Internacional de Educação Ambiental em Belgrado, na lugoslávia em 1975, orientava para que fossem inseridas no Programa Internacional de Educação Ambiental de Estocolmo, a divulgação de "uma nova ética global que proporcionasse a erradicação da pobreza, da fome, do analfabetismo, da poluição e da dominação e exploração humana" (PELICIONI, 2005, p. 588). Desde então já se denunciava para a necessidade de programas de Educação Ambiental para construir mudança no comportamento e na conscientização para os cuidados com o ambiente. Ou seja, apontava para construir um sentimento de responsabilidade de todos pela degradação do ambiente.

Em 1977, com a I Conferência Intergovernamental de Educação Ambiental realizada em Tbilisi, iniciou-se um processo em nível global para que fossem criadas condições para a formação de "uma nova consciência sobre o valor da natureza e para reorientar a produção de conhecimento baseada nos métodos da interdisciplinaridade e nos princípios da complexidade (JACOBI 2005, p. 190). A proposta era incluir a Educação Ambiental em todas as áreas da formação, em todas as modalidades de formação e como processo permanente.

Na Rio 92, no Brasil, a Educação Ambiental foi tema presente em todas as propostas da Agenda 21 buscando as transformações sociais necessárias ao combate à pobreza, levando a população à obtenção de meios de subsistência sustentáveis que conduziram a reorientar uma sociedade humana (PELICIONI, 2005). Essas temáticas se relacionam com as questões de cuidado do ambiente.

A temática da Educação Ambiental é tão relevante que culmina com a implementação da Política Nacional de Educação Ambiental com a aprovação da Lei Federal n 9.795, de 27 de abril de 1999, que prevê em seu "Art. 1. ${ }^{\circ}$ Entendem-se por educação ambiental os processos por meio dos quais o 
indivíduo e a coletividade constroem valores sociais, conhecimentos habilidades, atitudes e competências voltadas para a conservação do meio ambiente, bem de uso comum do povo, essencial à sadia qualidade de vida e sua sustentabilidade" construindo o conceito do que é a Educação Ambiental, mas que vai além pois prescreve em seu artigo $2^{\circ}$ que: "A Educação Ambiental é um componente essencial e permanente da educação nacional, devendo estar presente, de forma articulada, em todos os níveis e modalidades do processo educativo, em caráter formal e não formal”. Tais dispositivos da Lei reafirmam a relevância do que se entende por Educação Ambiental, mas que vai além definindo sua oferta em todos os níveis de formação.

A Política Nacional de Educação Ambiental, Lei Federal no 9.795, de 27 de abril de 1999, estabelece princípios claros e disciplina objetivos a serem alcançados $^{5}$ pela Educação Ambiental no Brasil. Ainda a mesma legislação reconhece a necessidade da inclusão de formação permanente e continuada para os educadores que devem tratar da Educação Ambiental.

O desenvolvimento da sociedade e os avanços da tecnologia apontam inúmeros benefícios em diversas áreas: telecomunicações, medicina, transporte, educação, porém este desenvolvimento deve ocorrer em equilíbrio com o ambiente e com a preservação e proteção de todos os ecossistemas. Este é um desafio que só pode ser alcançado com novos modelos de desenvolvimento e com a implementação de políticas de Educação Ambiental. Até o momento o desenvolvimento econômico é entendido como crescimento e, portanto, com um custo de uso e apropriação dos "bens naturais". No contexto do desenvolvimento e meio ambiente ainda predomina a perspectiva

5 Art. $4^{\circ}$. São princípios básicos da educação ambiental:

III - o pluralismo de ideias e concepções pedagógicas, na perspectiva da inter, multi e transdisciplinar;

IV - a vinculação entre ética, a educação, o trabalho e as práticas sociais;

$\mathrm{V}$ - a garantia de continuidade e permanência do processo educativo;

$\mathrm{VI}$ - a permanente avaliação crítica do processo educativo;

Art. $5^{\circ}$. São objetivos fundamentais da educação ambiental:

I - o desenvolvimento de uma compreensão integrada do meio ambiente em suas múltiplas e complexas relações, envolvendo aspectos ecológicos, psicológicos, legais, políticos, sociais, econômicos, científicos, culturais e éticos.

III - o estimulo e o fortalecimento de uma consciência crítica sobre a problemática ambiental e social;

IV - o incentivo à participação individual e coletiva, permanente e responsável, na preservação do equilíbrio do meio ambiente, entendendo-se a defesa da qualidade ambiental como um valor inseparável do exercício da cidadania;

VII - o fortalecimento da cidadania, autodeterminação dos povos e solidariedade com fundamento para o futuro da humanidade. 
de exploração dos recursos do planeta que, Guimarães (2001, p. 235), caracteriza como uma crise de impacto ao planeta, "o que configura o esgotamento de um estilo de desenvolvimento ecologicamente predador, socialmente perverso, politicamente injusto, culturalmente alienado e eticamente repulsivo". Essa perspectiva não está em sintonia com o que prescreve o Direito Ambiental e nem a legislação sobre o modelo de Educação ambiental.

Apesar da autonomia do Direito Ambiental e da existência de uma política nacional de Educação Ambiental no Brasil as políticas de desenvolvimento ainda estão focadas no crescimento econômico sem considerar de fato os impactos ao meio ambiente. Vale ressaltar, que o debate sobre meio ambiente, sustentabilidade e educação ambiental ganha constantemente contribuições que demonstram a dinâmica, riqueza e importância desses temas para o desenvolvimento da sociedade atual e das futuras gerações e, especialmente para a construção de novas relações entre os seres humanos e a natureza.

Não faltam, portanto, dispositivos normativos que sustentam uma nova perspectiva do Direito Ambiental, faltam respostas eficazes, faltam respostas que asseguram os direitos. Falta a percepção de que é urgente uma alteração das relações com a natureza como condição, inclusive, de sobrevivência de todos os seres humanos. O que se pretende é avançar em dois aspectos relacionados com o Direito Ambiental: desenvolvimento sustentável e a relação seres humanos e natureza, como projetos permanentes em todas as dimensões da Educação Ambiental.

\section{A teoria do Bem Viver e a relação com desenvolvimento sustentável}

A análise da legislação sobre Direito Ambiental e Educação ambiental, apontam para a necessidade de consolidar uma concepção de desenvolvimento sustentável que está em conformidade com o Relatório Brundtland de 1987, conhecido como "Nosso futuro comum", que indica um conceito de desenvolvimento como sendo: "aquele que atende às necessidades do presente sem comprometer a possibilidade de as gerações futuras atenderem às suas próprias necessidades" (PÁDUA, 2009). Afirma-se que é uma perspectiva jurídica que aponta necessariamente para uma relação 
harmoniosa dos seres humanos com a natureza, em todos os aspectos: ecológicos, ambiental, social, político, econômico, demográfico, cultural, institucional e espacial.

Para tal perspectiva de desenvolvimento sustentável é preciso reconhecer que a natureza é detentora de direitos. Essa perspectiva aponta para a definição de novos parâmetros da relação seres humanos e natureza. É necessário, portanto, uma nova visão sobre a natureza, ou como afirma Leis (1999, p. 214): "São poucos os que enxergam corretamente que o reducionismo antropocêntrico foi reforçado na modernidade porque os indivíduos tornaram-se sujeitos de direito ao serem considerados todos relativamente iguais, sendo impossível então atribuir o mesmo direito àqueles que, evidentemente, não são "tão" iguais a nós". Continua o mesmo autor: "O aumento da separação com o mundo natural dá-se, por consequência, porque a modernidade tende a obscurecer (ou assumir como transgressão) qualquer relação não racional entre os seres humanos" (LEIS, 1999, p. 214). Esta é a visão predominante que ainda marca a nossa sociedade, de uma supremacia dos seres humanos e que deve ser superada.

O atual movimento do Constitucionalismo Latino Americano passa a considerar a natureza como um verdadeiro sujeito de direitos. Os textos Constitucionais do Equador (2008) e da Bolívia (2009) reconhecem a existência de mais de um povo e de mais de um governo em suas constituições, identificando a pluralidade e a diversidade que são trabalhados pela chamada teoria do bem viver. Tal reconhecimento também é adotado pelas Nações Unidas que a partir do ano de 2009, na Resolução Harmonia com a Natureza, pela Assembleia Geral, reconhece a diversidade das populações. Essas mudanças estão intimamente relacionadas com 0 reconhecimento da necessidade de estabelecer uma nova relação com a natureza. "A Harmony with Nature são conversações que vêm acontecendo desde 2009 com a criação do dia mundial da Mãe-Terra - dia 22 de abril recepcionadas pela Assembleia Geral das nações Unidas em algumas resoluções, com destaque para a de número 67 , que reconheceu diretrizes antes apontadas pela Rio+20 de que a terra é a nossa casa; da necessidade de se estabelecer uma relação de harmonia com a natureza" (Oliveira, 2016, p. 113). 
Nessa perspectiva de assegurar direitos da natureza podem ser citados os artigos da Constituição do Equador de 2008: "Art. 71.-La naturaleza o Pacha Mama, donde se reproduce y realiza la vida, tiene derecho a que se respete integralmente su existencia y el mantenimiento y regeneración de sus ciclos vitales, estructura, funciones y procesos evolutivos" (Constituição do Equador, acessado em outubro de 2017) e da Constituição da Bolívia de 2009: Artículo 8. I. El Estado asume y promuve como principios ético-morales de la sociedad plural: suma qamaña (vivir bien), ñandereko (vida armoniosa), teko kavi (vida buena), ivi maraei (tierra sin mal) y qhapaj ñan (camino o vida noble) (Constituição da Bolívia, acessado em outubro de 2017). Tais dispositivos revelam uma perspectiva de direito ambiental que exige viver em harmonia e em equilíbrio com o entorno. É a indicação de uma forma de se relacionar com a natureza, de buscar o viver bem.

Reconhecer a natureza como detentora de direitos pode ser uma das respostas à grave crise socioambiental que está em nosso entorno. Reconhece-se as limitações dessa perspectiva, especialmente no campo da juridicização das relações sociais. Quem serão os demandantes para os direitos da natureza? Como buscar a garantia desse direito? O que a defesa de um direito da natureza apresenta é a denúncia de que os critérios de uma visão antropocêntrica de direito ambiental é uma visão limitada e que não responde as demandas do contexto atual. É necessário o estabelecimento de uma nova relação com a natureza.

Em harmonia com esta perspectiva do Direito Ambiental podemos citar as normativas 39 da Rio +20 , que na sua Declaração reconhece:

39. Reconhecemos que o planeta Terra e seus ecossistemas são a nossa casa e que a expressão "Mãe Terra" é comum em vários países e regiões e que alguns países reconhecem os direitos da natureza no contexto da promoção do desenvolvimento sustentável. Estamos convencidos de que, para alcançar um justo equilíbrio entre as necessidades econômicas, ambientais e sociais das gerações presentes e futuras, é necessário promover a harmonia com a natureza.40. Lançamos um apelo para a adoção de abordagens holísticas e integradas do desenvolvimento sustentável que orientarão a humanidade a viver em harmonia com a natureza e liderarão os esforços para restabelecer a saúde e a integridade do Planeta Terra. (Documento da Rio $+20,2012$ ). 
Os princípios da Declaração são fundamentos jurídicos para a construção de um novo paradigma do Direito Ambiental. É imprescindível que essas perspectivas relacionem as normas jurídicas de Direito Ambiental e as políticas de Educação Ambiental. A Agenda 2030 para o Desenvolvimento Sustentável assumida pela ONU, aponta em seu preâmbulo: "Estamos determinados a assegurar que todos os seres humanos possam desfrutar de uma vida próspera e de plena realização pessoal, e que o progresso econômico, social e tecnológico ocorra em harmonia com a natureza." (Organização das Nações Unidas, 2017). E define uma Visão que reconhece a necessidade de construir "9. (...) Um mundo em que a humanidade viva em harmonia com a natureza e em que animais selvagens e outras espécies vivas estão protegidos" (Organização das Nações Unidas, 2017). Aponta ainda como objetivo para consolidar tal matriz o seguinte: "12.8 Até 2030, garantir que as pessoas, em todos os lugares, tenham informação relevante e conscientização para o desenvolvimento sustentável e estilos de vida em harmonia com a natureza" (Organização das Nações Unidas, 2017). Ha a necessidade da construção de um bem viver, ou, um viver melhor e que seja em condições de sobrevivência das espécies, entre elas os seres humanos. Vanessa Hasson de Oliveira (2016) afirma que a garantia dos direitos humanos poderá ser alcançada pelo resgate de um modo de vida em plenitude, que despreze a ideia de viver melhor somente a partir do desenvolvimento econômico ou mesmo do desenvolvimento sustentável e avança para atingir o objetivo de permanecer em equilíbrio e harmonia com os demais seres para (co)criar a vida.

Considerando esses desafios é possível perceber a necessidade de defender o direito a um ambiente saudável e sustentável e apontar mecanismos que efetivem os direitos que já estão positivados e apontem para a implementação de novos direitos na área ambiental. Estamos propondo aqui uma leitura da construção contemporânea do bem viver. Entendendo que a teoria do bem viver é caracterizada pelo reconhecimento de quatro pontos de um paradigma existencialista de restrições ao uso da natureza:

(1) Aunque los seres humanos tienen características excepcionales (cultura, tecnología, etc. siguen siendo una especie entre otras que participan todas, de manera interdependiente, del ecosistema global; 
(2) los asuntos humanos están influenciados no sólo por factores sociales y culturales, sino también por relaciones complejas de causa-efecto y de retroacción en el sistema de la naturaleza [web of nature]; esto implica que las acciones humanas tiene numerosas consecuencias imprevisibles; (3) Los seres humanos viven en y dependen de un medio ambiente bio-físico finito que impone potentes restricciones físicas y biológicas a las acciones humanas; (4) Aunque las innovaciones de la humanidad y el poder asociado han podido parecer, en un momento, extender los limites de la capacidad de carga, las leyes ecológicas no pueden ser derogadas. (Vanhulst, Beling, 2013, p. 507).

Ou seja, o discurso do «bem viver» é baseado em um modelo cultural alternativo relacionado com a sua utopia. Desde suas origens na inspiração dos povos nativos, foi produzido na academia e provocou a construção de princípios que regulamentam dispositivos legais, especialmente no Equador e na Bolívia. É uma teoria que integra um modelo de denúncia dos limites da ideologia cultural dominante e apresenta respostas para os problemas centrais da vida coletiva, em particular, o problema da sustentabilidade. Na lógica que estamos desenvolvendo deve servir de base para a consolidação de um modelo de desenvolvimento que consolide políticas de proteção e cuidados com todos os seres que possibilite uma vida em um ambiente equilibrado e principalmente, assegurando meios de preservação de todas as espécies, de todos os seres e dos meios de vida que nos cercam. Desafios que depende de mudanças significativas que só podem ser alcançadas pela Educação Ambiental. Uma perspectiva que envolva todos os sujeitos da sociedade civil que estão direta ou indiretamente relacionados com processos de ligação entre os seres humanos e a natureza. Desde as atividades econômicas, tecnológicas, culturais, de governança pública, ou seja, todas que envolvam a natureza até as atividades da vida privada, do cotidiano de nossas ações.

\section{Considerações Finais}

A Constituição Federal de 1988 apresenta avanços significativos para o Direito Ambiental e para a Educação Ambiental. Indicam mudanças relevantes e que não são aplicáveis na permanência do velho paradigma antropocêntrico da relação dos seres humanos com a natureza, pois a definição de uma vida digna para todos os seres e o princípio intergeracional estabelecido como fundamentos da ordem jurídica ambiental somente serão implementados com a 
inauguração de um novo modelo de relação entre os seres humanos e a natureza.

A perspectiva, portanto, de assinalar para um novo modelo de desenvolvimento é inquestionável, inclusive o próprio texto constitucional aponta as expressões vida digna para todos e sustentabilidade com um princípio para o desenvolvimento de forma expressa. Ou seja, um modelo que deverá ser alcançado nesta nova ordem jurídica.

A teoria do bem viver está em sintonia com uma perspectiva de desenvolvimento que alcance todas as dimensões da vida: econômica, política, social, ambiental, demográfica, cultural, institucional e espacial. Nela estão evidenciadas perspectivas de respeito a diversidade, a pluralidade e a complexidade da vida coletiva nas sociedades modernas. Essas dimensões se evidenciam especialmente porque é um modelo cultural alternativo que inicia e se espalha pelo reconhecimento da existência de povos nativos e plurais no contexto da América Latina, especialmente no Equador e na Bolívia.

O desafio é indicar políticas de desenvolvimento sustentável que incluam como referências essa nova relação dos seres humanos com a natureza e, também, fazer com que este modelo seja o fundamento para as tomadas de decisão política. A perspectiva de incluir essa temática nas pesquisas desenvolvidas no contexto de implementação do Programa de Mestrado em Desenvolvimento e Políticas Públicas da UFFS, Campus Cerro Largo, RS é uma ferramenta para que as pesquisas e os estudos realizados considerem a necessidade de sistematizar e apontar espaços de possibilidade para este novo paradigma: uma natureza detentora de direitos e, portanto um modelo de Educação Ambiental onde o peso e a importância de todos os seres que compõe essa natureza seja o mesmo.

\section{Referências}

BRASIL. Lei n $^{\circ} 9795$ de 27 de abril de 1999. Institui a Política Nacional de Educação Ambiental. Brasília, 1999.

BRASIL. Ministério do Meio Ambiente, 2017. Acesso em: 10 de set. de 2017.

CARSON, Rachel. Primavera Silenciosa. 2. ed. São Paulo: Portico, 1962. 
CONSTITUIÇÃO DA BOLÍVIA. Disponível em: https://www.oas.org/dil/esp/Constitucion Bolivia.pdf: Acesso em: 10 out. de 2017.

CONSTITUIÇÃO DO EQUADOR. Disponível em: https://www.oas.org/juridico/pdfs/mesicic4 ecu const.pdf. Acesso em: 10 out. de 2017.

DERANI, Cristiane. Direito ambiental econômico. 3ª . Edição. São Paulo: Max Limonad, 2008.

DOCUMENTO DA RIO +20. 2012. Disponível em: http://www.rio20.gov.br/sobre a rio mais 20/estrategia-de-compensacao.html, Acesso em: 10 out. de 2017.

GUIMARÃES, Mauro. Educação Ambiental Crítica. Brasília. Ministério do Meio Ambiente, 2001.

JACOBI, Pedro. Educação ambiental, cidadania e sustentabilidade. Cadernos de Pesquisa, São Paulo, n. 118. março 2003.

JACOBI, Pedro. Educação Ambiental: o desafio da construção de um pensamento crítico, complexo e reflexivo. Educação e Pesquisa, São Paulo, v.31, n.2, mai/ago. 2005.

LEIS, Héctor Ricardo. A modernidade insustentável: as críticas do ambientalismo à sociedade contemporânea. Petrópolis, RJ: Vozes; Santa Catarina: UFSC, 1999.

OLIVEIRA, Vanessa Hasson de. Direitos da Natureza. Rio de Janeiro: Lumen Juris, 2016, p. 113

ORGANIZAÇÕES DAS NAÇÕES UNIDAS. 2017. Disponível em: https://nacoesunidas.org/pos2015/agenda2030/. Acesso em: 10 out. de 2017.

PÁDUA, José Augusto (org). Desenvolvimento, Justiça e meio ambiente. Belo Horizonte: Editora UFMG; São Paulo: Peirópolis, 2009.

PELICIONI, Maria Cecília Focesi. Educação ambiental: Evolução e conceitos. In: Saneamento, Saúde e Ambiente. São Paulo: Manole, 2005.

VANHULST, Julien e BELING, Adrián E. El Buen vivir: una utopía latinoamericana en el campo discursivo global de la sustentabilidad. Polis, Revista Latinoamericana, v. 12, n. 36, 2013. 